\title{
EDITORIAL
}

\section{COP 21: Acuerdo contra el cambio climático en Paris}

La Cumbre de París cierra un acuerdo histórico contra el cambio climático. Era la señal que muchos esperaban desde que los responsables de la mayoría de países del mundo comenzaron a discutir sobre el cambio climático hace más de dos décadas. Del mismo modo, era la señal que muchos inversores, atrapados ahora entre las dudas, querían oír para saber hacia dónde dirigir su dinero (1). El presidente francés, Fancois Hollande, manifiesta que se trata del "primer acuerdo universal de la historia de las negociaciones climáticas" y de la mejor oportunidad para "cambiar el mundo" (2), y el presidente de Estados Unidos, Barack Obama, considera que es la decisión más ambiciosa de la historia, porque "establece el marco sostenible que el mundo necesita para resolver la crisis climática" (3).

Este acuerdo, definido también como convención internacional y que entrará en vigor a partir de 2020, tiene por objeto, conforme con su artículo 2 , reforzar la respuesta mundial a la amenaza del cambio climático, en el contexto del desarrollo sostenible y de los esfuerzos por erradicar la pobreza, y para ello plantea: a) mantener el aumento de la temperatura media mundial muy por debajo de $2{ }^{\circ} \mathrm{C}$ con respecto a los niveles preindustriales, y proseguir los esfuerzos para limitar ese aumento de la temperatura a $1,5^{\circ} \mathrm{C}$ con respecto a los niveles preindustriales, reconociendo que ello reduciría considerablemente los riesgos y los efectos del cambio climático; b) aumentar la capacidad de adaptación a los efectos adversos del cambio climático y promover la resiliencia al clima y un desarrollo con bajas emisiones de gases de efecto invernadero, de un modo que no comprometa la producción de alimentos; y c) elevar las corrientes financieras a un nivel compatible con una trayectoria que conduzca a un desarrollo resiliente al clima y con bajas emisiones de gases de efecto invernadero (4).

Para lograr estos objetivos, los países se comprometen a evitar las emisiones lo antes posible y efectuar el proceso de reducción de manera rápida. Este plan de mitigación irá con un plan de financiación. Los países deben fijar cada cinco años sus objetivos nacionales de reducción de emisiones de gases de efecto invernadero. Hasta hoy, 186 de los 195 países participantes en la cumbre ya lo han hecho (5). El primer análisis de la ejecución de los planes será el 2018 y la primera actualización al alza ocurrirá el 2020 (6). El Protocolo de Kioto apostó por fijar metas obligatorias individuales a cada país, y solo logró cubrir el $11 \%$ de las emisiones mundiales, bajo este nuevo acuerdo a los países desarrollados se les fijan mayores exigencias. Por ejemplo, se establece que ellos deberán "seguir encabezando los esfuerzos" en reducción de emisiones; asimismo para la financiación, los países movilizarán un fondo de 100 mil millones de dólares anuales a partir de 2020, y desde 2025, se revisará al alza. A este fondo también podrán aportar los países emergentes, aunque de manera voluntaria. El fondo anual se destinará para que los Estados con menos recursos puedan adaptarse al cambio climático; por ejemplo, con medidas de protección por el aumento del nivel del mar. También servirán para que esos mismos países puedan crecer económicamente pero con bajas emisiones de dióxido de carbono (1).

Elevar los "flujos financieros" tendrá un efecto positivo para caminar hacia una economía baja en emisiones de gases de efecto invernadero, cuya sobreacumulación en la atmósfera por las actividades humanas ha desencadenado el cambio climático (1).

La conferencia finalmente ha dado sus frutos, los 195 países reunidos después de dos semanas de polémicas negociaciones, han alcanzado un gran acuerdo, que ahora para su vigencia deberá ser ratificado por 55 países que representen al menos $55 \%$ de las emisiones globales de gases de efecto invernadero.

Una de las razones por el que el acuerdo de Copenhague fue considerado un "fracaso" por las organizaciones ambientales, es que al carecer de efectos vinculantes, el pacto no tenía la suficiente validez que le permitiera ejecutar lo que se había acordado. La otra gran diferencia es el tema del aumento de la temperatura global. Fue en 
Copenhague donde se estableció el límite de $2{ }^{\circ} \mathrm{C}$, pero es en París donde queda fijada hasta el $1,5^{\circ} \mathrm{C}$.

El acuerdo tiene el enorme mérito de ser vinculante, decisión asumida para mantener en la lucha contra el cambio climático a todos los países firmantes. Estos se comprometieron a emprender de manera voluntaria, no vinculante, los objetivos de reducción de emisiones. Como dijo la ministra de Medio Ambiente sudafricana, Edna Molewa, al hablar en representación de los 130 países emergentes y en vías de desarrollo, el acuerdo "no es perfecto", pero constituye "una base sólida, a partir de la cual podemos lanzar un accionar intensificado con renovada determinación" (7).

\section{Referencias bibliográficas:}

1. Planelles M. la Cumbre de París cierra un acuerdo histórico contra el cambio climático. El País. [Online]. 2015 Dic. [cited 201512 14. Available from: http://internacional. elpais.com/internacional/2015/12/12/ actualidad/1449910910_209267.html

2. El Comercio [Internet]. COP21: "Acuerdo climático será un gran acto para la humanidad". El Comercio. [Online]. 2015 Dic. 12 9:25. Available from: http://elcomercio.pe/mundo/ medio-ambiente/cop2 1 -acuerdo-climaticogran-acto-humanidad-noticia-1863276

3. El Comercio. Barack Obama en la COP21: "Esto es enorme". El Comercio. [Online]. 2015 Dic. 12 19: 21. Available from: http:// elcomercio.pe/mundo/medio-ambiente/ barack-obama-sobre-acuerdo-cop2 1 -estoenorme-noticia-1863336

4. Naciones Unidas. Convención Marco de Cambio Climático [Ïnternet]. París: Conferencia de las Partes. [Online]. 2015 Dic. 12. Aprobación del Acuerdo de París. Available from: http://unfccc. $\mathrm{int} / \mathrm{resource/docs/2015/cop21/spa/l09s.pdf}$

5. BBC. COP21: Aprueban histórico acuerdo contra cambio climático en la Cumbre de París. BBC Mundo. [Online]. 2015 Dic. 12. Available from: http://www.bbc.com/mundo/ noticias/2015/12/151211_cumbre_clima_ paris_cop21_acuerdo_az
6. Arévalo C. 195 países firman histórico acuerdo en la COP21 de París. La República. 2015 Dic, $13 ; 23$.

7. Le Bourger. El mundo se pone de acuerdo para frenar el cambio climático. El Comercio. 2015 Dic. 13; A18.

Wilfredo Bulege Gutiérrez

Editor 